\title{
Avaliação Psicossocial e Desenvolvimento da Criança: Uma História de Vida
}

\author{
Jacqueline Meireles ${ }^{1}$ \\ Ana Paula Gomes Moreira \\ Programa de Pós-Graduação em Psicologia da Pontifícia Universidade Católica \\ de Campinas, Campinas, São Paulo, Brasil \\ Adinete Sousa da Costa Mezzalira \\ Faculdade Martha Falcão, Manaus, Amazonas, Brasil \\ Raquel Souza Lobo Guzzo \\ Departamento de Pós-Graduação em Psicologia da Pontifícia Universidade Católica \\ de Campinas, Campinas, São Paulo, Brasil
}

\section{Resumo}

Este artigo apresenta as características de uma proposta de avaliação psicossocial no contexto da escola pública, desenvolvida no âmbito do programa "Voo da Águia". Utilizou-se a metodologia de estudo de caso para a construção da história de vida de uma criança a partir de três fontes documentais que evidenciam a visão da mãe, professora e da psicóloga escolar sobre o desenvolvimento da criança: diários de campo, entrevista semiestruturada e de uma escala de avaliação de pais sobre o desenvolvimento dos seus filhos. Os fundamentos teóricos da Psicologia Social da Libertação sustentam a compreensão de desenvolvimento humano e de atuação psicológica, que orientam esta produção. O método propõe a condução de um processo construtivo-interpretativo que visa analisar o conteúdo dos documentos escritos e elaborar categorias explicativas. Assim, foram explicitadas as relações entre as situações de violência vividas e o processo de desenvolvimento da criança, bem como as possibilidades para a elaboração de propostas de intervenção no interior do "Voo da Águia" e para o âmbito da Psicologia Escolar.

Palavras-chave: Avaliação psicossocial, desenvolvimento infantil, psicologia escolar.

\section{Psichosocial Assessment and Child Development: A Life Story}

\begin{abstract}
This paper presents features of a proposal for psychosocial assessment in the context of public schools, developed in the "Voo da Águia" program. Case study methodology was used to build the story of a child's life based on three documentary sources that show the vision of the mother, teacher and school psychologist about the child's development: field diaries, a semi-structured interview and an assessment scale of parents about their children's development. The Social Psychology of Liberation theoretical foundations sustains the understanding of human development and psychological performance that guides
\end{abstract}

Endereço para correspondência: Rua Amadeu Martins, 375, Jd. Chapadão, Campinas, SP, Brasil 13070-006. E-mail: jacmeireles@gmail.com, anapaulaa.moreira@gmail.com, adinetecosta@hotmail.com e rguzzo@mpc. com.br

Este artigo é derivado do projeto de iniciação científica da aluna de Graduação Jacqueline Meireles, desenvolvido no período de Agosto de 2011 a Julho de 2012, sob financiamento do Conselho Nacional de Desenvolvimento Científico e Tecnológico (CNPq). 
this paper. The method proposes to conduct a constructive-interpretative process that aims to analyze the content of the documents and draft explanatory categories. Thus, we explained the relationship between situations of violence and child's development process, as well as possibilities for the development of proposals of action within the "Voo da Águia" and the scope of School Psychology.

Keywords: Psychosocial assessment, child development, school psychology.

\section{Evaluación Psicosocial y Desarrollo del Niño: Una Historia de Vida}

\section{Resumen}

Este artículo presenta las características de una propuesta de evaluación psicosocial en el contexto de las escuelas públicas, desarrolladas en el programa "Voo da Águia". Para subrayarlas, se ha utilizado la metodología de estudio de caso para construir la historia de vida de un niño a partir de tres fuentes documentales que muestran la visión de la madre, maestra y psicóloga de la escuela sobre el desarrollo infantil: diarios de campo, una entrevista semi-estructurada, y de una escala de evaluación de los padres sobre el desarrollo de sus hijos. A partir de los fundamentos teóricos de la Psicología Social de la Liberación se comprende el desarrollo humano y la acción psicológica que guían esta producción. El método propone realizar un proceso constructivo interpretativo que tiene como objetivo analizar el contenido de los documentos escritos y elaborar categorías explicativas. Así, hemos explicado la relación entre las situaciones de violencia y el proceso de desarrollo de los niños, como también las posibilidades para la elaboración de propuestas de acción en el interior del programa "Voo da Águia" y para el ámbito de aplicación de la Psicología Escolar.

Palabras clave: Evaluación psicosocial, desarrollo infantil, psicología escolar.

O presente artigo pretende apresentar as características de um processo de avaliação psicossocial construído no interior da proposta de intervenção denominada "Voo da Águia" que tem sido desenvolvida pelo Grupo de Pesquisa Avaliação e Intervenção Psicossocial: Prevenção, Comunidade e Libertação ${ }^{2}$ no contexto das escolas públicas do município de Campinas. Para tanto, construiremos um estudo de caso que deve explicitar as ações que caracterizam esta modalidade de avaliação. A condução de uma análise a partir da apresentação de um caso exemplar visa permitir à pesquisa o alcance de detalhes cujas singularidades devem favorecer a compreensão do que propomos.

Para isso, é importante compreender o que significa considerar a atuação do psicólogo no contexto da escola pública inserida na sociedade capitalista. As características de opressão, desi-

2 Grupo de Pesquisa da Pontifícia Universidade Católica de Campinas (PUC Campinas). gualdade e violência anunciam dimensões importantes para o desenvolvimento das crianças neste espaço e, portanto, para o psicólogo que nele se insere. Assim, a apresentação do programa "Voo da Águia", bem como dos fundamentos teóricos que o envolvem, deve orientar a apreciação do nosso percurso metodológico consequente, de modo a promover a elaboração de uma síntese que contribua para a reflexão sobre o papel do psicólogo escolar.

\section{Fundamentação Teórica}

O "Voo da Águia" é um programa de intervenção que foi fundado no ano $2000 \mathrm{e}$, desde então, vem sendo desenvolvido nas escolas públicas do município de Campinas-SP. Ele foi gestado no interior dos projetos de pesquisa que tem conduzido a produção do grupo nos espaços educativos e comunitários (Guzzo, 2000). Envolvendo elementos de ensino, pesquisa e extensão, o programa prevê a realização de estudos e pesquisas que fundamentem a inserção de psi- 
cólogos como membros das equipes educativas presentes no cotidiano da escola.

A literatura consolidada na área da Psicologia Escolar tem enfatizado que o psicólogo é o profissional apto para acompanhar o desenvolvimento das crianças e explicitar a sua relação com os processos de ensino e aprendizagem. Nesse sentido, acentua-se que o conteúdo da ação psicológica constitui condição para a realização do trabalho pedagógico conduzido, essencialmente, pelo professor (Guzzo, 2007, 2009; Machado, 2003; Marinho-Araújo \& Almeida, 2005; Tanamachi, 2007).

Todavia, o avanço teórico consolidado pela área não corresponde à realidade da situação do psicólogo escolar nas escolas públicas brasileiras. Embora a Lei de Diretrizes e Bases para a Educação Nacional (LDB, 1996) mencione o psicólogo como profissional relacionado à dinâmica educativa, ainda não existe legislação que assegure a sua inserção.

Ao refletir sobre esta situação, o trabalho de Souza (2010) mapeou os serviços oferecidos por psicólogos nas Secretarias Municipais de Educação do Estado de São Paulo e os seus resultados indicaram que dos 133 municípios investigados, apenas 61 contrataram psicólogos como profissionais. A partir dessa conjuntura, o trabalho de Guzzo, Mezzalira e Moreira (2012) refletiu sobre a inserção do psicólogo no sistema educativo tomando como base os relatórios apresentados no Seminário Nacional do Ano da Educação. Os resultados deste estudo indicam a presença de psicólogos nas escolas de estados como Rio de Janeiro, Alagoas, Maranhão e Paraíba, ainda que em condições não universalizadas. No entanto, muitos destes psicólogos estão vinculados às Secretarias de Saúde e cedidos para Secretarias de Educação.

Especificamente na região de Campinas-SP, onde o "Voo da Águia" está inserido, a legislação não prevê a inserção de psicólogos na Secretaria de Educação, nem mesmo por meio de contratos com a Secretaria de Saúde. Esta particularidade explicita, portanto, as características que envolvem o desenvolvimento do "Voo da Águia" bem como seus limites e perspectivas. Vinculado a uma iniciativa acadêmica, o "Voo da Águia" pretende, a um só tempo, envolver pesquisas que contribuam para o esclarecimento do papel do psicólogo escolar e fomentar o espaço necessário para o debate acerca da dinâmica política e legal que assegure a inserção dos psicólogos escolares como profissionais efetivos nas escolas públicas.

Quanto às suas especificidades, o "Voo da Águia" propõe o acompanhamento do desenvolvimento das crianças a partir da atuação cotidiana. Isto significa a participação nos espaços administrativos, técnicos e pedagógicos, além da relação com os dispositivos da Assistência e Saúde. A metodologia utilizada para esta inserção vem sendo desenvolvida ao longo dos trabalhos do grupo e envolvem instrumentos variados como diários de campo, entrevistas e escalas (Costa, 2005; Guzzo \& Tizzei, 2007; Mezzalira \& Guzzo, 2011; Sant'Ana, Costa, \& Guzzo, 2008; Weber, 2005).

A sua proposta de inserção cotidiana retoma os fundamentos anunciados por Martín-Baró (1990, 1996, 2000) no campo da Psicologia Social da Libertação e, assim, explicita a relação entre a Psicologia Escolar e a Psicologia Comunitária. Esta relação se traduz pela compreensão de que o psicólogo deva participar das demandas sociais e por meio delas desenvolver suas propostas de atuação, além do que, estando a escola inserida em uma comunidade, o trabalho dos profissionais da educação afeta a comunidade e, da mesma forma, as demandas da comunidade afetam o trabalho na escola. Esta intervenção tem sido denominada como intervenção psicossocial (Guzzo, Moreira, \& Mezzalira, 2011). Outros grupos brasileiros endossam essa perspectiva (Oliveira, Ximenes, Coelho, \& Silva, 2008), que também vem sendo retomada e divulgada por pesquisas internacionais (Burton, 2013; Montero, 2010).

Assim, a intervenção psicossocial visa apreender as condições e circunstâncias que envolvem os processos de desenvolvimento, buscando explicitar como elas contribuem ou dificultam para a consolidação de um desenvolvimento pleno e emancipador. Ao compreender a relação entre escola e comunidade a partir desta perspectiva relacional, amplia-se a compreensão acerca 
dos processos de desenvolvimento infantil, de modo a considerar as dimensões de trabalho, desigualdade social e violência que os envolvem. Do interior da Psicologia Social da Libertação, Martín-Baró $(2000)^{3}$ compreende a violência não como um fenômeno abstrato e destituído da materialidade contextual. Ao contrário, a violência é compreendida no âmbito das relações sociais, no interior das quais ela é expressa e reproduzida.

Segundo esta concepção, a existência de relações de violência é oriunda de uma dinâmica social desigual. Assim, ele não isola a violência como um fenômeno entre indivíduos, mas enfatiza as dimensões estruturais, a disputa pelo poder social e econômico e as condições objetivas de vida. As relações de trabalho, moradia e acesso aos serviços públicos são permeadas pela violência que assume formas de opressão, disputa e exploração.

A partir desta explicação, o autor chama atenção para uma questão importante: a dinâmica relacional de violência oriunda de uma estrutura social desigual constitui a dinâmica no interior da qual a maioria das pessoas se desenvolve biológica, social e psicologicamente. Desta perspectiva, Martín-Baró (1990) se detém, especialmente, sobre o desenvolvimento das crianças e enfatiza o impacto de determinadas circunstâncias no momento da vida em que este processo se intensifica. Na busca de compreendê-las, a partir desta dimensão relacional, ele propõe o conceito de situação-limite, para enfatizar que circunstâncias concretas é que constituem o processo de subjetivação e, portanto, de desenvolvimento das crianças. O profissional que acompanha este desenvolvimento não pode se omitir da contingência cotidiana que o constitui.

O desenvolvimento do "Voo da Águia", dessa forma, explicita um fundamento teórico de origem materialista. A Psicologia Materialista, segundo sugere Tolman (1989) é aquela que

Para saber mais sobre a vida, a obra e a concepção teórica de Ignácio Martín-Baró consultar: Ibánez, L de la C. (2000). La psicología de Ignacio Martín-Baró como psicología social crítica. Una presentación de su obra. Revista de Psicología General y Aplicada, 53(3), 437-450. admite a consciência como função determinada pelas contingências da realidade material. Nesse sentido, as características econômicas, políticas e sociais são tomadas como fonte das relações humanas.

A escola, como parte constitutiva deste tecido social, produz e reproduz tais características. Sem a sua consideração, portanto, tanto o processo de desenvolvimento das crianças, quanto as ações do psicólogo são destituídas de sentido. Por isso, reiteramos a importância de que se reflita sobre o que, de fato, constituem estas ações e a que elas servem. Enfatizamos que a sua prioridade é conhecer as crianças que se desenvolvem, como sujeitos de sua história, perscrutando-a a partir de várias fontes acessíveis ou criadas pelo psicólogo escolar. A intervenção organizada pelo Voo da Águia propõe que o psicólogo esteja atento às situações-limite que acontecem ao longo do desenvolvimento da criança, dentro e fora da escola. Esta é a proposta de intervenção que vem sendo elaborada pelo "Voo da Águia" ao longo dos seus 13 anos de existência. Seu objetivo é buscar compreender as singularidades da vida de cada criança e, assim, contribuir para o desenvolvimento pedagógico no âmbito do processo de escolarização.

Para os propósitos deste trabalho, contudo, o que propomos é a condução de um estudo de avaliação, que demonstre, praticamente, o fundamento teórico que anunciamos. Apresentaremos uma história singular cujas dimensões revelam a relação que se constitui entre condições e circunstâncias materiais de vida e as características do desenvolvimento.

No entanto, não associamos características objetivas a possibilidades máximas de desenvolvimento. Ao contrário, compreendemos que a condução de um processo de avaliação como este, fornece as bases para a elaboração de modelos ou propostas de intervenção que visem a superação dos limites impostos por condições objetivas.

\section{Método}

Nosso percurso metodológico pretende apresentar o que chamaremos de "Biografia de 
José4". Ele visa desvelar como a ação psicológica pode angariar elementos importantes sobre uma vida sem dissociá-la de sua dinâmica social.

Como um programa de intervenção, o "Voo da Águia" envolve psicólogos e estudantes de Psicologia que, inseridos na escola, desenvolvem o processo de acompanhamento do desenvolvimento das crianças com o recurso de instrumentos variados, cujo conteúdo é incorporado a uma pasta de informações construída para cada criança $^{5}$. A história refletida neste estudo foi acompanhada no cenário de uma CIMEI (Centro Municipal Integrado de Educação Infantil) localizado em uma das regiões mais desiguais da cidade de Campinas/SP segundo dados da Prefeitura Municipal.

Para compor as dimensões da biografia proposta para este estudo, utilizaremos os documentos produzidos por um integrante do "Voo da Águia", constituintes da pasta de José, a saber: diários de campo, entrevista semiestruturada com a professora e uma escala de avaliação de pais sobre o desenvolvimento da criança, o Parent's Appraisal of Child Early Development (PACED) ${ }^{6}$, traduzida e adaptada semanticamente pela equipe do Laboratório de Avaliação e Medidas Psicológicas (LAMP) ${ }^{7}$ da PUC Campinas.

Os diários de campo são instrumentos que contém elementos descritivos e sintéticos, construídos a partir do olhar do psicólogo sobre a dinâmica vivenciada por ele na escola. A entrevista semiestruturada com a professora é composta

4 Usaremos um nome fictício para preservar a identidade da criança.

5 Para conhecer as especificidades desse procedimento, consultar Costa (2010).

6 Para a compreensão dos detalhes de tradução e adaptação do PACED consultar: Guzzo, R. S. L., Marques, C. A. E., Machado, E. M., \& Tizzei, R. P. (2007). Conhecendo as famílias: Descrição do instrumento, relato dos procedimentos e caracterização dos participantes. In R. S. L. Guzzo (Ed.), Desenvolvimento infantil: Família, proteção $e$ risco (pp. 23-33). Campinas, SP: Alínea.

7 O LAMP é coordenado pela $\mathrm{Dr}^{\mathrm{a}}$. Raquel Souza Lobo Guzzo na PUC Campinas. por perguntas disparadoras sobre o comportamento da criança na sala de aula, sua relação com os colegas e os aspectos de autonomia, iniciativa e expressividade observados pelo professor com relação à criança. O PACED abarca questões de identificação da composição familiar bem como elementos do desenvolvimento da criança a partir do ponto de vista da mãe e um espaço para o relato da mãe sobre as experiências de vida da criança.

Nesse sentido, optamos por um procedimento de análise que conduzisse uma síntese interpretativa a partir do confronto entre o conteúdo destes três documentos tomados como fonte para a análise, de modo a resultar na construção de um estudo de caso, a 'Biografia de José'. Segundo Lüdke e André (1986), o estudo de caso é uma técnica produtiva para o desenvolvimento de pesquisas no âmbito da Educação porque enfatiza as singularidades do processo educacional na diversidade de relações que o compõem. Por isso, a escolha do estudo de caso como técnica nesta pesquisa explicita nosso esforço de síntese a partir dos procedimentos que estruturam a atuação dentro da Escola.

A condução da síntese interpretativa como procedimento de análise está sustentada pela elaboração de González-Rey (2002), desenvolvida em uma sequencia de procedimentos que envolvem a leitura confrontada dos documentos com os objetivos da pesquisa, a identificação de trechos desses documentos que expressam unidades de sentido ao expressar dimensões determinantes para o entendimento da informação guardada e a união destas unidades de sentido em categorias que as representem.

Construídas as categorias a partir dos diferentes documentos, foi possível confrontá-las entre si, de modo a construir uma síntese que refletisse a "Biografia de José". Para facilitar o entendimento deste percurso, optamos por apresentá-lo sob a forma de resultados. Em um primeiro momento, apresentamos a síntese que condensa a história de José e, em seguida, ampliamos seus sentidos na apresentação de informações importantes 'na visão da mãe', 'na visão da professora' e 'na visão da psicóloga'. 


\section{Resultados}

\section{E Agora José?8}

José era uma criança de quatro anos, que estudava em uma escola municipal em um bairro da periferia de Campinas. José sofria, mas o sofrimento em si não era percebido pelos professores. O que os preocupavam eram os comportamentos externos de José. Um dia, o pai de José é assassinado em frente à escola, após tê-lo deixado. A situação assusta e mobiliza toda a comunidade e a equipe escolar. Para José, porém, era mais do que uma situação de violência em seu cotidiano: Seu pai já não o buscaria na escola.

\section{Categorias}

Na Visão da Professora. A professora contribui com informações a respeito do comportamento de José no cotidiano escolar. Assim, temos acesso à forma como a criança se relaciona com os pares e com as atividades propostas. Quando solicitada para falar abertamente acerca de José, a professora destaca que José é uma criança que parece não sentir-se parte do grupo, pois quando a professora propõe alguma atividade, ele sempre questiona "E eu?", "E o meu?", “Еu não vou ter? Eu quero!". A professora afirma também que a criança está num momento em que não gosta de dividir as coisas, por isso está sempre envolvido em brigas e disputas. Esta questão se aplica aos relacionamentos com os colegas, visto que José se incomoda e agride as pessoas com quem seus amigos se relacionam. Desta forma, a professora destaca que a criança está sempre envolvida em confusões, e quando não está presente, a sala trabalha de forma mais tranquila. Sobre os interesses de José, a professora destaca seu gosto por estórias infantis, apesar de ainda não saber identificar letras e números.

$\mathrm{Na}$ Visão da Mãe. Por meio da entrevista com a mãe, acessamos a visão da mãe tanto a respeito de sua família, a família de José, como a respeito das experiências de vida da criança.

$8 \quad$ Inspirado no poema 'José' de Carlos Drummond de Andrade.
1. Família de José. José é filho único do casal. Maria, empregada doméstica de vinte e três anos, e Pedro, que faleceu aos vinte e um anos e trabalhava como artesão no presídio. Ambos começam um relacionamento aos quinze e treze anos, respectivamente e cinco anos depois geram José. Apesar de a criança ter uma boa relação com os pais, cresce queixando-se do distanciamento de ambos: o pai passa grande parte de sua infância numa prisão e a mãe precisa trabalhar muitas horas por dia para sustenta-los. À época da entrevista, José vivia com a mãe, o avô materno, duas tias e uma prima de nove anos.

2. Experiências de vida. Dentre as experiências vividas por José destacam-se, no relato da mãe, algumas situações. A primeira é a vivência da prisão do pai, aos dois anos de idade. José leva algum tempo até compreender o que significa o fato de o pai estar preso. Mas esta situação o afeta à medida que a criança só pode ver o pai quinzenalmente, e por um tempo limitado. José ansiava pelo dia da visita, sobre a qual falava durante toda a semana.

A segunda situação aqui destacada é a vivência da morte do pai. Aos quatro anos de idade, José passou oito meses vivendo com o pai em liberdade. O pai dava-lhe a atenção que a mãe, por trabalhar muito, não podia lhe dar, além de leva-lo e busca-lo na escola. $\mathrm{O}$ assassinato ocorreu em frente à escola, quando o pai o deixou. A mãe relata que contar a notícia foi muito doloroso, pois sabia que a ligação de José com o pai era muito forte e sente que ele está sofrendo muito com a perda.

Finalmente, destaca-se a resposta que Maria dá à psicóloga quando esta lhe pergunta se havia uma figura de homem com o qual José se identifica: seu irmão, um tio de José que está preso há dois anos. Ela sempre o leva para visitá-lo na prisão, e ele respeita muito esse tio.

Na Visão da Psicóloga. Os elementos destacados na análise dos diários de campo contri- 
buíram para melhor compreensão da dinâmica cotidiana escolar de José, bem como das experiências vividas pela criança. Foram analisados e separados em cinco categorias: Desinteresse, Dificuldades, Relações Sociais, Familia e Comunidade e Professora/Escola. Para cada categoria, trazemos trechos dos diários de campo com situações ilustrativas.

1. Desinteresse. Esta categoria abrange as falas relacionadas ao comportamento de José durante as aulas, caracterizadas pela psicóloga como distração ou desinteresse em relação às atividades propostas. "O José como sempre fica distante das atividades, não participa, ainda não observei alguma atividade que o interesse. Ele fica muito na dele, como se não estivesse naquele lugar, não se sente incluído naquele espaço" (DC05).

2. Dificuldades. Alguns trechos dos diários de campo apresentaram dificuldades enfrentadas por José em relação às atividades propostas em aula. " $O$ José ficava totalmente alheio à brincadeira, não conseguia nem entender que para descobrir o segredo teria que observar as peças do colega. Apesar de ter quatro anos, ele não conseguia entender a brincadeira" (DC04).

3. Relações sociais. Muitos trechos tratam das relações sociais de José, mostrando como este lida com os colegas, e com os adultos. A Psicóloga relata alguns momentos em que participa de conflitos com colegas, ora porque os provoca, ora por causa de brinquedos, necessitando sempre da mediação de um adulto.

A questão da criança não sentir-se parte do grupo aparece, também, em outros diários de campo, sendo bastante enfatizada pela psicóloga:

Quando a colega de sala ficou falando o nome dele e pedindo para parar, ele perguntou: "Como você sabe o meu nome? Como ela sabe o meu nome?". O José acha que por não fazer parte do grupinho dela, ela não teria como saber o seu nome. Ele tem uma dificuldade tremenda para se incluir no grupo, vive o mundo dele, encontra-se na maior parte do tempo aéreo, como se fosse uma pessoa que ocupa um lugar apenas fisicamente. (DC02)

4. Familia e comunidade. A Psicóloga faz constantes referências à família de José, bem como à comunidade em que está inserido, permitindo uma melhor compreensão de seu ambiente de desenvolvimento. A Psicóloga destaca a contribuição da mãe, que a recebe com grande satisfação: “. . . disse-me que queria mesmo o acompanhamento do seu filho, pois estava muito preocupada com ele" (DC03).

Sobre o pai da criança, observamos relatos nos diários de campo que reproduzem falas das professoras, explicitando como elas compreendiam a morte de Pedro (seu pai): é apresentado como alguém que vivia em conflito com muitas pessoas:

De acordo com a professora o pai do José não era um sujeito bem visto na comunidade, era "bicho bravo" e devia para muita gente, ninguém gostava dele, enfatizou que ele não era "peça boa". Falou que ele foi atropelado logo após deixar ofilho na escola. Ela disse-me que foram os bandidos - no caso o padrasto [de Pedro] está incluido que fizeram isto. Atropelaram o pai, depois passaram por cima novamente - quebrando as pernas - e em seguida descarregaram a arma nele, foi "uma morte bem matada", este tipo de assassinado é um aviso para a comunidade. Sempre matam desta forma quando alguém é devedor e metido a valentão. (DC06)

Em outro momento a psicóloga relata a visão de uma das professoras sobre o pai de José, como alguém muito violento.

Segundo a professora, este pai já tinha matado um monte no bairro e na frente de crianças. Ela disse isto porque a mãe comentou para mim que foi melhor ter ocorrido este assassinato depois que deixou o filho na escola. (DC07)

Os diários de campo revelam também de que forma a morte do pai tem afetado os comportamentos da criança na escola. A morte do pai traz grande sofrimento a José: Fomos ao parque e a professora veio con- 
versar comigo sobre o José, dizendo que está muito preocupada com ele, pois ele sempre chora na hora da saída. Isto vem ocorrendo porque a criança era buscada pelo pai no horário e agora que vem buscar é uma tia e ela chega sempre atrasada, deixando a criança angustiada. (DC08)

Sobre a comunidade, a psicóloga destaca que as crianças sentem-se amedrontadas e inseguras diante da violência que as cerca. Histórias como "o tarado da mala", que esquartejou uma criança e a colocou numa mala, e temores a respeito da polícia permeiam o cotidiano das crianças:

[A professora] Disse que além da história do tarado da mala, a criança falou hoje no passeio que a policia leva as crianças para a casa de abrigo. . . . Outra professora diz que é impossivel às crianças não terem medo de policial, porque sempre que um helicóptero sobrevoa o bairro, todos ficam com armas apontadas para cima, isto faz a criança ter medo da polícia, porque todos têm. (DC09)

5. Professoralescola. É possível identificar nos relatos a forma como a equipe escolar lida com a situação da morte do pai de José. A Psicóloga destaca o comentário de uma das professoras sobre a família de José:

Falei para as educadoras que ele tinha uma vinculação muito forte com o tio, mas que ele estava preso, fazendo a professora levantar o seguinte comentário: "olha o tipo de vinculação que esta criança vai construir, todo mundo esta preso, olha o exemplo". (DC07).

Outra professora busca recursos para proteger as crianças da cena de violência, em especial José, visto que a vítima era seu pai. Ela imediatamente fez uma roda com as crianças e ficou contando historinhas para as crianças enquanto o carro de policia e ambulância ia passando, visto que o assassinato ocorreu nas proximidades da escola. ... Falou-me que conversou com a criança dizendo no ouvido dele que sabia o que tinha acontecido com o pai dele e falou que sempre que ele quisesse um "colinho", ela teria um para dar. (DC06)

Respeitando um pedido da mãe, todos na escola concordam em omitir detalhes do assassinato, buscando formas de proteger José. No geral, a mãe recomenda que ninguém comente com o seu filho como foi a morte do pai, ela disse que ele foi atropelado, não entrou em detalhes com a criança. . . A professora concordou e disse que realmente não havia necessidade de discutir estes detalhes com a criança, porque não traria nenhum beneficio, o que poderíamos fazer era trabalhar a perda deste pai com a criança. (DC07)

É importante destacar a riqueza e potencialidade deste momento em que mãe, professora e psicóloga estão juntas buscando recursos para intervir de modo a amenizar o sofrimento da criança.

\section{Discussão e Conclusões}

A história de José nos permite refletir sobre as diversas singularidades que perpassam o cotidiano escolar, bem como nos leva a pensar sobre o papel do profissional de psicologia neste espaço. O que ele deve fazer?

A experiência do Voo da Águia tem demonstrado que estas singularidades constituem, exatamente, a possibilidade da sua ação. Em conformidade com a proposta da Psicologia Social da Libertação, a inserção do psicólogo no cotidiano escolar, possibilita ultrapassar a aparência dos comportamentos e investigar relações.

Materializar esta proposta na construção da avaliação do caso de José nos permitiu a contraposição de diversos pontos de vista, junto à professora, à mãe e a partir da própria observação da psicóloga durante o período em que esteve na escola. Tal contraposição expande a compreensão dos nexos e determinantes que avançam da vida comunitária para a escola e da vida escolar para a comunidade. Uma análise de um comportamento isolado pode indicar uma criança desinteressada. Mas o que significam o desinteresse aparente ou a dificuldade de interação social? 
A avaliação inspirada pela Psicologia Social da Libertação revela a compreensão do desenvolvimento humano a partir de uma perspectiva materialista. Nesse sentido, os documentos considerados ao longo do processo de avaliação guardam a relação entre as condições objetivas da vida da criança e sua família e as dimensões do seu desenvolvimento na escola. No caso de José, estas condições objetivas referem-se, por exemplo, às peculiaridades da convivência familiar: o pai está preso e a mãe passa a maior parte do dia no trabalho comprometida com a necessidade de sobrevivência da família. Compreender a relação destas condições concretas com o processo de desenvolvimento psíquico é prerrogativa da Psicologia e o processo de avaliação aqui demonstrado vale-se de recursos como os diários de campo, entrevista e escala para investigar a qualidade desta relação.

A partir desta compreensão, entende-se que a violência vivida nas contradições de uma sociedade estruturada na desigualdade social, os sentimentos de medo e insegurança são tão reais para José e sua família como para as outras famílias da comunidade.

Uma situação como a relatada pela professora quando menciona como José se surpreende ao ser chamado pelo nome pelos colegas explicita uma circunstância particular cujo conteúdo requer a singularidade do olhar do psicólogo. Reconhecê-lo como uma característica especial no interior do processo de desenvolvimento de uma criança específica sem destituí-la de sua inserção social, pode permitir ao psicólogo a elaboração de propostas de intervenção também específicas. A partir dos dados organizados por esta avaliação, é possível observar que os comportamentos de José em sala de aula (distração, brigas com os pares, dificuldades para acompanhar tarefas) não devem ser entendidos como problemas da criança ou da família, mas vistos em seus multideterminantes.

Nesse sentido, a ideia de situação-limite definida por Martín-Baró (1990) agrega elementos para a compreensão da relação entre as situações de violência e o processo de desenvolvimento infantil. Assim, reconhecemos que o processo de desenvolvimento não é um fenômeno abstrato, mas intimamente relacionado à objetividade da vida social. Os limites impostos pela violência também iluminam as relações possíveis para os profissionais que se envolvem com as crianças dentro e fora da escola no interior e para além do "Voo da Águia". Desta perspectiva, as situações-limites aglutinam dimensões objetivas e subjetivas das relações promotoras do desenvolvimento, indicando suas máximas possibilidades.

\section{Referências}

Burton, M. (2013). Psicologia da Libertação: Uma práxis crítica construtiva. Estudos de Psicologia (Campinas), 30(2), 249-259. doi:10.1590/ S0103-166X2013000200011

Costa, A. S. (2005). Psicólogo na escola: Avaliação do projeto "Voo da Águia" (Dissertação de mestrado, Pontifícia Universidade Católica de Campinas, SP, Brasil).

Costa, A. S. (2010). Desenvolvimento da criança na educação infantil: Uma proposta de acompanhamento (Tese de doutorado, Pontifícia Universidade Católica de Campinas, SP, Brasil).

González-Rey, F. (2002). Pesquisa qualitativa em psicologia: Caminhos e desafios. São Paulo, SP: Pioneira Thompson.

Guzzo, R. S. L. (2000). Risco e proteção: Busca de indicadores para uma intervenção preventiva (Projeto de pesquisa CNPq, Pontifícia Universidade Católica de Campinas, SP, Brasil).

Guzzo, R. S. L. (2007). Escola amordaçada - Compromisso do psicólogo com esse contexto. In A. M. Martínez (Ed.), Psicologia escolar e compromisso social (pp. 17-29). Campinas, SP: Alínea.

Guzzo, R. S. L. (2009). Revolução na Psicologia Escolar: As demandas da realidade escolar e do profissional na escola. In M. R. Souza \& F. C. S. Lemos (Eds.), Psicologia e compromisso social - Unidade na diversidade (pp. 75-90). São Paulo, SP: Escuta.

Guzzo, R. S. L., Mezzalira, A. S. C., \& Moreira, A. P. G. (2012). Psicólogo na rede pública de educação: Embates dentro e fora da própria profissão. Psicologia Escolar e Educacional, 16(2), 329338. doi:10.1590/S1413-85572012000200016

Guzzo, R. S. L., Moreira, A. P. G., \& Mezzalira, A. S. C. (2011). Avaliação psicossocial: Desafio para a prática profissional nos contextos educativos. Avaliação Psicológica, 10(2), 163-171. 
Guzzo, R. S. L., \& Tizzei, R. P. (2007). Olhar sobre a criança: Perspectiva de pais sobre o desenvolvimento. In R. S. L. Guzzo (Ed.), Desenvolvimento infantil: Família, proteção e risco (pp. 35-57). Campinas, SP: Alínea.

Lei de Diretrizes e Bases para a Educação Nacional. (1996, 23 dez.). Lei n ${ }^{\circ}$ 9.394, de 20 de dezembro de 1996. Diário Oficial da União.

Lüdke, M., \& André, M. E. D. A. (1986). Pesquisa em educação: Abordagens qualitativas. São Paulo, SP: Editora Pedagógica e Universitária.

Machado, A. M. (2003). Os psicólogos trabalhando com a escola: Intervenção a serviço do que? In M. E. M. Meira \& M. A. M. Antunes (Eds.), Psicologia Escolar: Práticas críticas (pp. 63-85). São Paulo, SP: Casa do Psicólogo.

Marinho-Araújo, C. M., \& Almeida, S. F. C. (2005). Psicologia Escolar - Construção e consolidação da identidade profissional. Campinas, SP: Alínea.

Martín-Baró, I. (1990). Guerra y trauma psicosocial del niño salvadoreño. In I. Martín-Baró (Ed.), Psicología social de la guerra: trauma y terapia (pp. 35-39). San Salvador, El Salvador: Universidad Centroamericana "José Simeón Canas" Editores.

Martín-Baró, I. (1996). O papel do psicólogo. Estudos de Psicologia (Natal), 2(1), 7-27.

Martín-Baró, I. (2000). Violencia y agresion social. In I. Martín-Baró, Acción y ideologia: psicología social desde Centroamerica (pp. 359-423). San Salvador, El Salvador: Universidad Centroamericana "José Simeón Canas" Editores.

Mezzalira, A. S. C., \& Guzzo, R. S. L. (2011). Acompanhamento e promoção do desenvolvimento na educação infantil: Algumas contribuições da Psicologia Escolar. Aletheia, 35(36), 22-35.
Montero, M. (2010). Crítica, autocrítica y construcción de teoría en la psicología social latinoamericana. Revista Colombiana de Psicología, 19(2), 177-191.

Oliveira, F. P., Ximenes, V. M., Coelho, J. P. L., \& Silva, K. S. (2008). Psicologia Comunitária e educação libertadora. Psicologia: Teoria e Prática, 10(2), 147-161.

Sant'Ana, I. M., Costa, A. S., \& Guzzo, R. S. L. (2008). Escola e vida: Compreendendo uma realidade de conflitos e contradições. Pesquisas e Práticas Psicossociais, 2(2), 302-311.

Souza, M. P. R. (2010). A atuação do psicólogo na rede pública de educação: Concepções, práticas e desafios (Tese de livre docência, Instituto de Psicologia, Universidade de São Paulo, SP, Brasil).

Tanamachi, E. R. (2007). A psicologia no contexto do materialismo histórico dialético: Elementos para compreender a psicologia histórico-cultural. In M. E. M. Meira \& M. G. D. Facci (Eds.), Psicologia Histórico-Cultural - Contribuições para o encontro entre a subjetividade e a educação (pp. 63-92). São Paulo, SP: Casa do Psicólogo.

Tolman, C. W. (1989). For a materialist psychology. Recent Trends in Theoretical Psychology, 2, 3749.

Weber, M. A. (2005). Violência doméstica e rede de proteção: Dificuldades, responsabilidades $e$ compromissos (Dissertação de mestrado, Pontifícia Universidade Católica de Campinas, SP, Brasil) 